\title{
Effect of Low-Dose Atorvastatin on Plasma Concentrations of Adipokines in Patients with Metabolic Syndrome
}

\author{
Magdalena Szotowska Beata Czerwienska Marcin Adamczak Jerzy Chudek \\ Andrzej Wiecek \\ Department of Nephrology, Endocrinology and Metabolic Diseases, Medical University of Silesia, Katowice, Poland
}

\section{Key Words}

Metabolic syndrome $\cdot$ Obesity $\cdot$ Adiponectin $\cdot$ Statins

\begin{abstract}
Objective: It has not been conclusively proven whether or not the beneficial effect of statins on the cardiovascular system is mediated through their influence on adipokine secretion. We designed a prospective open-label study to assess the influence of 6 months' atorvastatin therapy on plasma concentrations of some adipokines in patients with metabolic syndrome. Subjects: 36 adult patients with metabolic syndrome and serum LDL cholesterol $>3.5 \mathrm{mmol} / \mathrm{l}$, previously untreated with statins, were included in the study. Measurements: Plasma concentrations of adiponectin, leptin, resistin and insulin were measured before initiation and after 2, 4 and 6 months of atorvastatin therapy $(10 \mathrm{mg})$, and 2 months after treatment cessation. Results: Treatment with atorvastatin was followed by a $35.6 \%$ decline in LDL cholesterol. Plasma adiponectin concentration decreased by $20.7 \%$ after 2 months; however, after 4 and 6 months, this did not differ significantly from the initial values. There was a negative correlation between the initial plasma concentration of leptin and changes in HDL cholesterol $(R=-0.358 ; p=0.04)$. Conclusions: Firstly, the long-term effect of atorvastatin
\end{abstract}

therapy in patients with metabolic syndrome is not mediated by changes in the secretion of adiponectin, leptin and resistin by adipose tissue. Secondly, plasma leptin concentration seems to be a predictor of $\mathrm{HDL}$ cholesterol changes during atorvastatin therapy.

Copyright $\odot 2012$ S. Karger AG, Basel

\section{Introduction}

Statins lower total and LDL plasma cholesterol concentrations and increase the concentration of the HDL fraction [1]. They also show some pleiotropic actions: anti-inflammatory, immunomodulatory, antithrombotic and fibrinolytic [2-4]. Moreover, statins enhance endothelial function, inhibit platelet activity, lower blood pressure and at least some of them decrease insulin resistance [5-7]. It has not been conclusively proven whether or not the above-listed advantageous actions of statins may be mediated, at least partially, through their influence on the secretion of adipokines, like adiponectin, leptin or resistin [8-10].

Adiponectin enhances metabolism of glucose and fatty acids in the liver and skeletal muscles, and inhibits gluconeogenesis in the liver $[11,12]$. It also possesses anti-

Prof. Dr hab. med. Andrzej Więcek, FRCP (Edin)

Department of Nephrology, Endocrinology and Metabolic Diseases

Medical University of Silesia in Katowice

ul. Francuska 20/24, PL-40-027 Katowice (Poland)

Tel. +48 322552 695, E-Mail awiecek@ spskm.katowice.pl 
atherogenic actions [13]. It has already been found that in patients with metabolic syndrome plasma adiponectin concentration is significantly decreased $[14,15]$. Recently, it has been shown that plasma adiponectin concentrations determine HDL cholesterol response to atorvastatin treatment [16].

Another protein produced by adipocytes is leptin. Plasma leptin concentrations are markedly elevated in obese patients, including those with metabolic syndrome [17]. In contrast to adiponectin, leptin exerts (at least in vitro) several proatherogenic effects, such as stimulation of inflammatory processes, oxidative stress, induction of endothelial dysfunction, blood pressure increase, platelet aggregation, hypertrophy and proliferation of vascular smooth muscle cells [18].

Patients with metabolic syndrome are also characterized by elevated plasma resistin concentrations compared to the general population [19]. Unlike adiponectin and leptin, resistin is mainly produced by macrophages of the fat tissue and takes part in obesity-related chronic inflammatory processes [20].

The potential mechanism of statins' influence on adipokine synthesis or biodegradation remains unknown. Regardless, the hypothesis concerning the modulation of adipokine synthesis or secretion in adipose tissue by statins has been tested in a few studies. Many of these did not prove the existence of a significant influence [16, 21-24]. Koh et al. [25] demonstrated an up to $12 \%$ decrease in plasma adiponectin concentration after 2 months of simvastatin therapy. In contrast, the opposite effect of atorvastatin was shown by Blanco-Colio et al. [26] in patients at high cardiovascular risk. The authors demonstrated a $9.7 \%$ increase in plasma adiponectin concentration in the whole group and a $24.7 \%$ increase in patients receiving the highest dose $(80 \mathrm{mg})$ of atorvastatin. Even greater, the $44 \%$ increase in plasma adiponectin was found by Miyagishima et al. [27] in a small $(\mathrm{n}=22)$ group of patients with ischemic heart disease treated for 3 months with atorvastatin. Recently, Ando et al. [28] and Qu et al. [29] confirmed that atorvastatin increases plasma adiponectin concentration. In the study by Ando et al. [28], in contrast to atorvastatin, pravastatin did not influence plasma adiponectin concentration.

We designed a single-centre prospective open-label study choosing atorvastatin as one of the most potent statins for lowering LDL cholesterol [30] with proven long-term efficacy in cardiovascular risk reduction [31] and pronounced pleiotropic actions [32]. Unlike the others, we selected only patients with metabolic syndrome, and we followed the therapy with atorvastatin longer than in the majority of previously performed studies (6 months) analyzing its influence on plasma concentrations of adiponectin, resistin and leptin.

\section{Patients and Methods}

Thirty-six Caucasians (17 males, 19 females) with metabolic syndrome and newly referred to our outpatient clinic with a total serum LDL cholesterol concentration $>3.5 \mathrm{mmol} / \mathrm{l}$, previously untreated with statins, were included into the study. Metabolic syndrome was diagnosed based on NCEP-ATP III criteria [33]. Patients had to match three of the criteria listed below: abdominal obesity (waist circumference: females $>88 \mathrm{~cm}$, males $>102 \mathrm{~cm}$ ); serum concentration of triglycerides $\geq 1.7 \mathrm{mmol} / \mathrm{l}$, low HDL cholesterol ( $<1.3 \mathrm{mmol} / \mathrm{l}$ for males and $<1.29 \mathrm{mmol} / \mathrm{l}$ for females); fasting serum glucose concentration $\geq 100 \mathrm{mg} / \mathrm{dl}$, arterial blood pressure $\geq 130 / 85 \mathrm{~mm} \mathrm{Hg}$. Patients with a BMI $<27$ or $>40$, elevated glutamic pyruvic transferase (GPT) serum activity, diabetes mellitus type 2 , or any chronic disease other than metabolic syndrome and arterial hypertension treated with antihypertensive drugs other than amlodipine (calcium channel blocker) were excluded from the study. The study protocol was accepted by the Local Ethics Committee of Medical University of Silesia. Each patient gave their written consent.

Before the initiation of treatment with $10 \mathrm{mg}$ atorvastatin (Sortis ${ }^{\circledR}$ ), anthropometric measurements (body weight, height, waist circumference), whole-body X-ray densitometry DEXA were obtained and blood samples were taken during fasting for the estimation of serum concentrations of glucose, cholesterol and its fractions, triglycerides, GPT activity, and plasma concentration of insulin, adiponectin, leptin and resistin. All patients received a standard $10-\mathrm{mg}$ dose of atorvastatin for 6 months and a low-lipid diet was recommended. The effect of lipid-lowering therapy over 6 months of atorvastatin treatment was monitored by measurement of serum LDL cholesterol levels in 2-month intervals. The protocol specified cessation atorvastatin treatment and exclusion from the study if the GPT activity exceeded twice the upper limit.

Patients received recommendations for a low-fat diet. However, maintenance of a stable body weight during the period of observation was strongly encouraged as its variability makes the interpretation of changes in adiponectin, leptin concentrations and insulin resistance difficult. Therefore, the low-calorie diet and weight reduction were (temporarily) not stressed.

All measurements, except DEXA, were repeated every 2 months, and 2 months after treatment cessation. The second DEXA measurement was performed at the end of the 6-month follow-up period.

All patients with metabolic syndrome suffering from arterial hypertension were treated with amlodipine (5-10 $\mathrm{mg} /$ daily). In the previous studies, it has been shown that antihypertensive treatment with amlodipine influences neither plasma leptin nor adiponectin concentrations [34].

Twenty healthy volunteers (11 females, 9 males) served as a control group. All laboratory tests in the control group were performed only once. 
Table 1. Characteristics of patients with metabolic syndrome and control group

\begin{tabular}{lccc}
\hline & $\begin{array}{l}\text { Metabolic syndrome } \\
(\mathrm{n}=36)\end{array}$ & $\begin{array}{c}\text { Control group } \\
(\mathrm{n}=20)\end{array}$ & $\mathrm{p}$ \\
\hline Age, years & $51(42-58)$ & $49(32-61)$ & 0.77 \\
Gender (males/females) & $17 / 19$ & $9 / 11$ & 0.87 \\
BMI & $29.7(27.7-32.2)$ & $23.5(20.9-24.5)$ & $<0.001$ \\
Total body fat mass, kg & $31.3(26.0-36.6)$ & - & - \\
Trunk fat mass, kg & $16.7(14.0-20.4)$ & - & - \\
Waist circumference, cm & $103(91-107)$ & - & - \\
Systolic BP, mm Hg & $128(121-142)$ & $126(120-135)$ & 0.879 \\
Diastolic BP, mm Hg & $83(80-90)$ & $80(76-85)$ & 0.981 \\
Total cholesterol, mmol/l & $6.74(6.18-7.48)$ & $4.85(4.60-5.10)$ & $<0.001$ \\
HDL fraction, mmol/l & $1.29(1.12-1.50)$ & $1.42(1.34-1.53)$ & 0.06 \\
LDL fraction, mmol/l & $4.92(4.51-5.94)$ & $3.18(2.99-3.46)$ & $<0.001$ \\
Triglycerides, mmol/l & $1.66(1.38-2.20)$ & $1.15(0.93-1.30)$ & $<0.001$ \\
Glucose, mmol/l & $4.91(4.45-5.37)$ & $4.45(4.15-4.80)$ & 0.001 \\
Insulin, $\mu \mathrm{U} / \mathrm{ml}$ & $9.80(5.60-11.40)$ & $6.05(4.55-8.50)$ & 0.003 \\
QUICKY index & $0.26(0.25-0.29)$ & $0.31(0.28-0.33)$ & 0.001 \\
Creatinine, $\mu \mathrm{mol} / \mathrm{l}$ & $80(72-90)$ & - & - \\
Adiponectin, $\mu \mathrm{g} / \mathrm{ml}$ & $8.54(7.09-10.42)$ & $9.83(8.15-11.78)$ & 0.04 \\
Leptin, ng/ml & $12.2(4.6-21.7)$ & $8.5(3.7-11.9)$ & $<0.001$ \\
Resistin, $\mathrm{ng} / \mathrm{ml}$ & $5.60(2.50-6.90)$ & $2.90(1.95-3.50)$ & 0.003 \\
& & &
\end{tabular}

Data are presented as medians with IQR in parentheses. $\mathrm{BP}=$ Blood pressure.

\section{Laboratory Measurements}

The enzyme immunoassay method was used for the measurement of plasma concentrations of adiponectin (B-Bridge International Inc., San Jose, Calif., USA), resistin (Bio Vendor Laboratory Medicine, Brno, Czech Republic) and insulin (Roche Diagnostics, Mannheim, Germany). An immunoradiometric method was used for the measurement of plasma concentrations of leptin (Linco Research Laboratories, St. Louis, Mo., USA). The other parameters were measured with standard methods.

Insulin sensitivity was calculated as the Quantitative InsulinSensitivity Check Index QUICKY index $=1 /[\log$ (plasma insulin level) $+\log ($ plasma glucose level)] [35].

\section{DEXA Measurement}

Lunar DPX-L scanner (Lunar Radiation Co., Madison, Wisc., USA) operated by a single experienced technician was used for all body measurements performed in a supine position. This method allows the assessment of total lean mass, total fat mass and fat mass of the trunk.

\section{Statistical Analysis}

Statistical analysis was performed using the Statistica 7.0 PL software. Data are presented as medians and IQR. Non-parametric tests (Mann-Whitney $U$ and $\chi^{2}$ ) were used to compare the groups. The effects of atorvastatin therapy were analyzed by Friedman's repeated ANOVA on ranks by comparing the relative changes in values in response to treatment. Wilcoxon signed-rank test was used to compare time point values before and after treatment. Correlation coefficients were calculated according to Spearman. Values of $\mathrm{p}<0.05$ were considered as statistically significant.

\section{Results}

Patients with metabolic syndrome were characterized by significantly higher mean BMI and serum concentrations of total cholesterol and its LDL fraction, glucose, insulin and HOMA-IR than the control group (table 1). As expected in patients with metabolic syndrome, plasma concentrations of leptin and resistin were about 2 times higher, while plasma adiponectin concentration was $17 \%$ lower, than in healthy controls (table 1).

Treatment with atorvastatin was followed by 28.6 and $35.6 \%$ declines in total cholesterol and its LDL fraction concentrations, respectively (fig. 1). Two and 6 months after initiation of this therapy, 72 and $61 \%$ of patients, respectively, obtained a concentration of LDL fraction within the recommended range $(<3.5 \mathrm{mmol} / \mathrm{l})$. Serum triglyceride concentrations also decreased significantly, while the fraction of HDL cholesterol increased slightly, but also significantly (table 2 ). The above-mentioned values were stable during the 6-month treatment period, and returned to initial values 2 months after discontinuation of the cholesterol-lowering medication.

During the 6 months of atorvastatin treatment in patients with metabolic syndrome, body mass decreased slightly by $1.25(0.17-2.23) \mathrm{kg}$, mainly as a consequence 
Table 2. Patient data before and after atorvastatin therapy

\begin{tabular}{|c|c|c|c|c|c|}
\hline & \multirow{2}{*}{$\begin{array}{l}\text { Before } \\
\text { atorvastatin therapy }\end{array}$} & \multirow{2}{*}{$\begin{array}{l}\text { After } 2 \text { months' } \\
\text { atorvastatin therapy }\end{array}$} & \multirow{2}{*}{$\begin{array}{l}\text { After } 6 \text { months' } \\
\text { atorvastatin therapy }\end{array}$} & \multicolumn{2}{|c|}{ Wilcoxon test } \\
\hline & & & & $\begin{array}{l}0 \text { vs. } 2 \\
\text { months }\end{array}$ & $\begin{array}{l}0 \text { vs. } 6 \\
\text { months }\end{array}$ \\
\hline Weight, kg & $84.1(79.5-88.7)$ & $83.7(79.1-88.3)$ & $82.9(78.2-87.6)$ & 0.01 & 0.01 \\
\hline Total fat mass, $\mathrm{kg}$ & $31.8(29.1-34.5)$ & - & $31.0(27.9-34.0)$ & - & 0.02 \\
\hline Fat mass of the trunk, $\mathrm{kg}$ & $17.4(16.0-18.7)$ & - & $16.8(15.3-18.3)$ & - & 0.02 \\
\hline Waist circumference, $\mathrm{cm}$ & $101(98-104)$ & - & $99(96-102)$ & - & 0.08 \\
\hline Glucose, $\mathrm{mmol} / \mathrm{l}$ & $4.91(4.73-5.08)$ & $5.11(4.88-5.34)$ & $5.09(4.85-5.32)$ & 0.03 & 0.07 \\
\hline Triglycerides, mmol/l & $1.82(1.52-2.06)$ & $1.47(1.20-1.73)$ & $1.51(1.21-1.81)$ & $<0.01$ & $<0.01$ \\
\hline Total cholesterol, mmol/l & $6.88(6.59-7.17)$ & $4.98(4.66-5.31)$ & $4.91(4.61-5.21)$ & $<0.01$ & $<0.01$ \\
\hline $\mathrm{SBP}, \mathrm{mm} \mathrm{Hg}$ & $131(126-136)$ & - & $132(126-138)$ & - & 0.56 \\
\hline $\mathrm{DBP}, \mathrm{mm} \mathrm{Hg}$ & $85(82-87)$ & - & $85(83-87)$ & - & 0.88 \\
\hline IL-6, pg/ml & $22.3(20.7-24.5)$ & $21.2(18.9-23.2)$ & $21.1(19.0-23.3)$ & 0.65 & 0.55 \\
\hline QUICKY index & $0.27(0.26-0.28)$ & $0.27(0.26-0.28)$ & $0.28(0.27-0.29)$ & 0.42 & 0.49 \\
\hline
\end{tabular}

Data are presented as means with 95\% CI in parentheses. SBP = Systolic blood pressure; DBP = diastolic blood pressure.

of declining body fat mass $(-0.9 \mathrm{~kg}$, including $-0.6 \mathrm{~kg}$ of trunk fat mass), while the QUICKY index and blood pressure were stable (table 2).

Plasma adiponectin concentration decreased by $20.7 \%$ after 2 months of atorvastatin treatment, but later the suppressive effect declined (fig. 1). Thus, after 6 months, plasma adiponectin concentration did not differ significantly from the initial values (table 1).

Treatment with atorvastatin did not significantly influence either plasma leptin or resistin concentrations at any time point in the protocol (fig. 1).

\section{Correlations}

There was no correlation between initial plasma concentrations of adiponectin or resistin and changes in LDL and HDL fractions of cholesterol during the 6-month therapy with a standard $10-\mathrm{mg}$ dose of atorvastatin. However, there was a negative correlation between initial plasma leptin concentration and changes in HDL cholesterol $(\mathrm{R}=-0.359 ; \mathrm{p}=0.04$; fig. 2$)$, but not for LDL cholesterol during atorvastatin therapy. There was an even stronger correlation between initial body fat mass and changes in HDL cholesterol $(\mathrm{R}=-0.419 ; \mathrm{p}=0.01)$, but not with changes in LDL cholesterol.

There was no correlation between changes in LDL and HDL fractions during 6-month atorvastatin therapy. We found a strong positive correlation between initial leptinemia and BMI ( $R=0.408 ; \mathrm{p}=0.031)$, total fat mass $(\mathrm{R}=$ $0.433 ; \mathrm{p}=0.013)$ and trunk fat mass $(\mathrm{R}=0.396 ; \mathrm{p}=0.025)$,

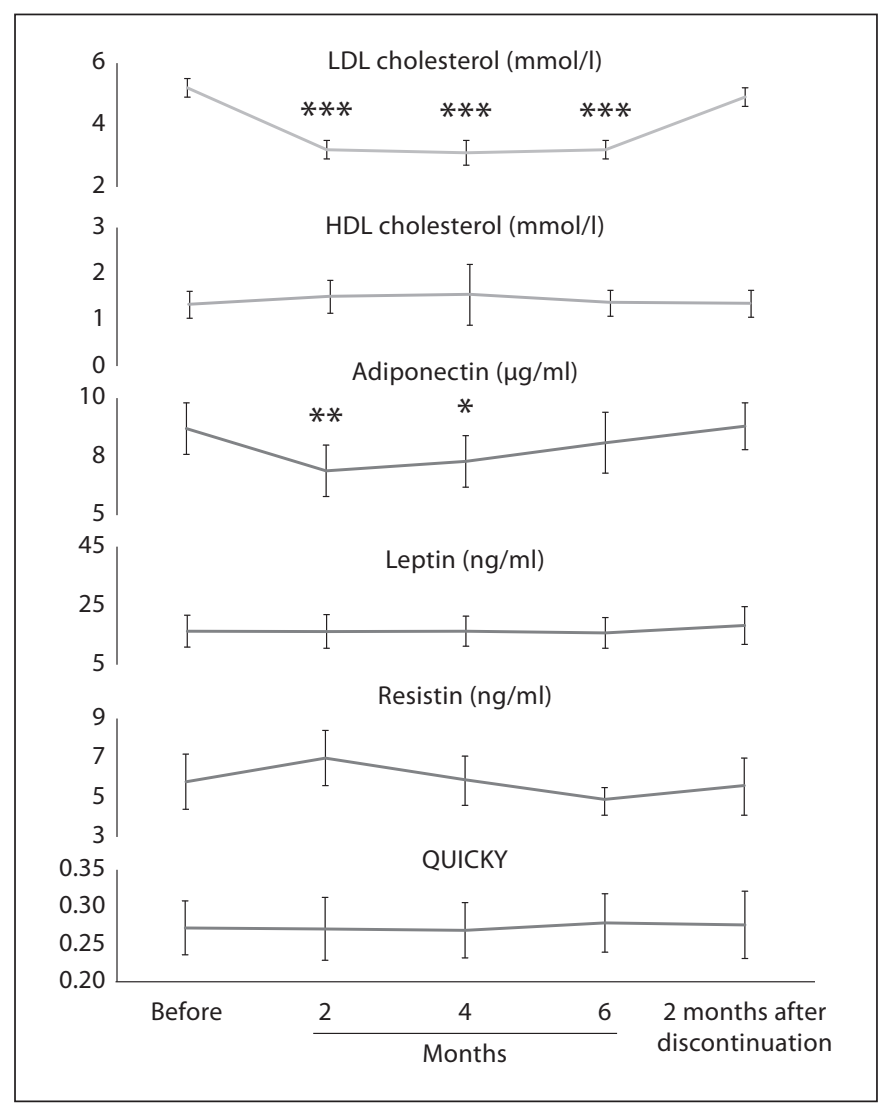

Fig. 1. The influence of 6 months' therapy with atorvastatin on serum LDL and HDL cholesterol and plasma adiponectin, leptin, resistin concentration and QUICKY index in patients with metabolic syndrome. ${ }^{*} \mathrm{p}<0.05,{ }^{* *} \mathrm{p}<0.01,{ }^{* *} \mathrm{p}<0.001$ vs. baseline. 


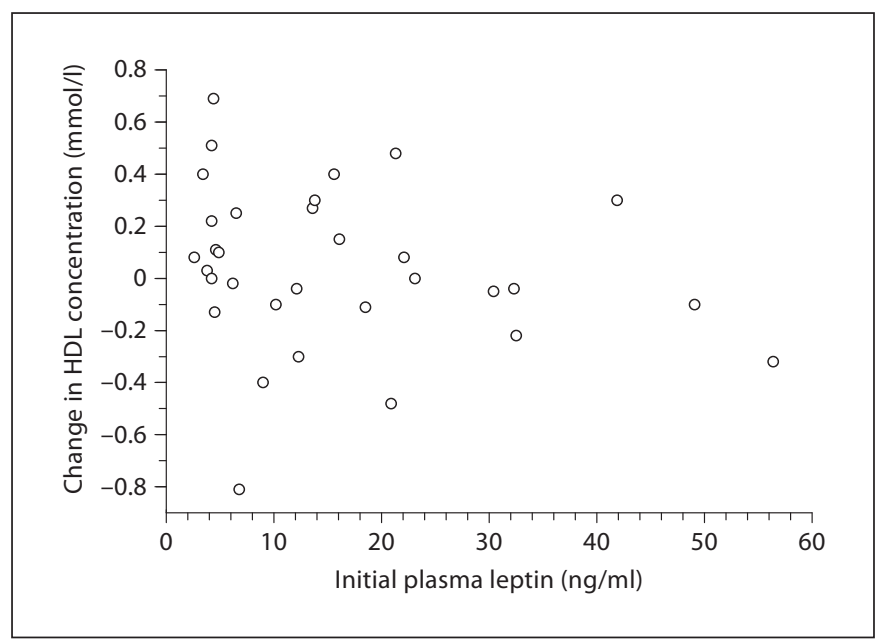

Fig. 2. The correlation between initial (prior to atorvastatin therapy) plasma leptin concentrations and observed changes in HDL concentration during 6 months' therapy with atorvastatin in patients with metabolic syndrome $(\mathrm{R}=-0.359 ; \mathrm{p}=0.04)$.

and between the same parameters at the end of the study $(\mathrm{R}=0.411, \mathrm{p}=0.030 ; \mathrm{R}=0.447, \mathrm{p}=0.010 ; \mathrm{R}=0.457, \mathrm{p}=$ 0.001 , respectively). We also observed strong negative correlations between initial leptin concentration and totallean mass $(\mathrm{R}=-0.421 ; \mathrm{p}=0.016)$ and between the same parameters at the end of the study $(\mathrm{R}=-0.431 ; \mathrm{p}=0.016)$. For adiponectin, we found a negative correlation with total fat mass at the beginning of the study $(\mathrm{R}=-0.352$; $\mathrm{p}=0.035)$ and at the end of atorvastatin treatment $(\mathrm{R}=$ $-0.337 ; \mathrm{p}=0.044)$.

\section{Discussion}

This study demonstrates that long-term atorvastatin therapy does not influence plasma concentrations of adiponectin, leptin and resistin in patients with metabolic syndrome. Moreover, we found that plasma leptin concentration determines the HDL cholesterol response during therapy with atorvastatin.

Downregulation of adiponectin expression is potentially harmful for the cardiovascular system; however, as we observed only a transient decrease in plasma adiponectin concentration during atorvastatin therapy, the long-term clinical significance of this change is questionable. This observation is in line with results of in vitro studies which revealed that atorvastatin directly downregulated expression of adiponectin in adipocytes [36]. Similarly, in vitro atorvastatin downregulated expression of leptin in adipocytes [36] and resistin in 3T3-L1 adipocytes and human preadipocytes and monocytes/macrophages [37]. The potential effect of atorvastatin on adipocyte metabolic pathways remains unknown.

The mentioned in vitro experiments were not supported by clinical studies. Blanco-Colio et al. [26] (in patients with high cardiovascular risk) and Miyagishima et al. [27] (in patients with ischemic heart disease) reported an increase in plasma adiponectin concentration after 3 months' therapy with atorvastatin. The exact reason for the discrepancy between our and the above-quoted studies remains unclear. Perhaps differences in the characteristics of studied populations concerning the status of insulin sensitivity and the low dose of atorvastatin $(10 \mathrm{mg}$ per day) are the explanations. Only in the current study did all the patients have metabolic syndrome, and therefore presumably lower insulin sensitivity. As claimed by Huptas et al. [38], even a low dose of atorvastatin, as used by us, is able to cause improvement in insulin sensitivity. Unfortunately, we were unable to prove the increase in insulin sensitivity, and perhaps the lack of it may indirectly explain the unaffected concentration of plasma adiponectin.

In our patients, we did not observe a decline in plasma leptin concentration, which was only reported by von Eynatten et al. [39] in a group of patients with type 2 diabetes mellitus after 8 weeks of atorvastatin therapy. Nevertheless, in this study initial and final body weights were not reported, making the interpretation of the obtained results $(39.6 \%$ reduction in initial plasma leptin concentration) difficult.

Moreover, we did not find any decline in plasma concentration of resistin followed by atorvastatin therapy, which had previously been reported by Shetty et al. [21] and von Eynatten et al. [39]. Such discrepancies are probably related to the low prescribed dose of atorvastatin (10 $\mathrm{mg} /$ day) in our study. Shetty et al. [21] used a dose that was twice as high and found a $16 \%$ decrease in plasma resistin levels. Interestingly, a similar decline in plasma resistin concentration was found in the group receiving placebo in the above-mentioned study. Thus, this study did not provide strong evidence of a suppressive effect of atorvastatin on resistin secretion.

An interesting finding is the negative correlation between the initial plasma leptin concentration and the extent of the increase in HDL cholesterol concentration after the 6-month atorvastatin therapy. Such an interrelation has not been previously reported. Thus, the marked increase in HDL cholesterol can be anticipated in patients with lower concentrations of leptin. In the current study, 
we have not confirmed the recently published data by van Hoek et al. [16] showing a relationship between baseline plasma adiponectin concentration and changes in plasma HDL cholesterol after atorvastatin treatment. In contrast to HDL cholesterol, neither this study nor that by van Hoek et al. [16] demonstrated the predictive role of plasma adipokine concentrations on LDL cholesterol-lowering efficacy of atorvastatin.

The presented study has several limitations. We used a low dose of atorvastatin as the pleiotropic action of statins is probably not related to the dose. However, we could not prove that higher doses of atorvastatin do not influence the secretion of studied adipokines. Moreover, we were unable to prevent the occurrence of changes in body weight in our group of patients. The observed changes were small but significant. The major limitation of the current study is the lack of a placebo group. Therefore, we are not able to prove whether the transient de- crease in plasma adiponectin is due to treatment or to other causes. This issue should be studied in future randomized controlled trials.

\section{Conclusion}

The long-term effect of atorvastatin therapy is not mediated by changes in the secretion of adiponectin, leptin and resistin by adipose tissue. Plasma leptin concentration seems to be a predictor of HDL cholesterol changes during atorvastatin therapy.

\section{Acknowledgment}

This study was supported by a grant from the Polish Ministry of Science and Higher Education.

\section{References}

-1 Deedwania PC, Hunninghake DB, Bays HE, Jones PH, Cain VA, Blasetto JW, STELLAR Study Group: Effects of rosuvastatin, atorvastatin, simvastatin, and pravastatin on atherogenic dyslipidemia in patients with characteristics of the metabolic syndrome. Am J Cardiol 2005;95:360-366.

$\checkmark 2$ Sakoda K, Yamamoto M, Negishi Y, Liao JK, Node K, Izumi Y: Simvastatin decreases IL-6 and IL-8 production in epithelial cells. J Dent Res 2006;85:520-523.

-3 Kobashigawa JA, Katznelson S, Laks H, Johnson JA, Yeatman L, Wang XM, Chia D, Terasaki PI, Sabad A, Cogert GA, et al: Effect of pravastatin on outcomes after cardiac transplantation. N Engl J Med 1995;333:621627.

4 Fenton JW 2nd, Jeske WP, Catalfamo JL, Brezniak DV, Moon DG, Shen GX: Statin drugs and dietary isoprenoids downregulate protein prenylation in signal transduction and are antithrombotic and prothrombolytic agents. Biochemistry 2002;67:85-91.

5 Wassmann S, Laufs U, Bäumer AT, Müller K, Ahlbory K, Linz W, Itter G, Rösen R, Böhm M, Nickenig G: HMG-CoA reductase inhibitors improve endothelial dysfunction in normocholesterolemic hypertension via reduced production of reactive oxygen species. Hypertension 2001;37:1450-1457.

6 Ichiki T, Takeda K, Tokunou T, Iino N, Egashira K, Shimokawa H, Hirano K, Kanaide H, Takeshita A: Downregulation of angiotensin II type 1 receptor by hydrophobic 3-hydroxy-3-methylglutaryl coenzyme A reductase inhibitors in vascular smooth muscle cells. Arterioscler Thromb Vasc Biol 2001;21:1896-1901.

7 Sonmez A, Baykal Y, Kilic M, Yilmaz MI, Saglam K, Bulucu F, Kocar IH: Fluvastatin improves insulin resistance in nondiabetic dyslipidemic patients. Endocrine 2003;22: 151-154.

-8 Sacks FM, Pfeffer MA, Moye LA, Rouleau JL, Rutherford JD, Cole TG, Brown L, Warnica JW, Arnold JM, Wun CC, Davis BR, Braunwald E: The effect of pravastatin on coronary events after myocardial infarction in patients with average cholesterol levels. Cholesterol and Recurrent Events Trial investigators. N Engl J Med 1996;335:10011009.

-9 Prevention of cardiovascular events and death with pravastatin in patients with coronary heart disease and a broad range of initial cholesterol levels. The Long-Term Intervention with Pravastatin in Ischaemic Disease (LIPID) Study Group. N Engl J Med 1998;339:1349-1357.

10 Schwartz GG, Olsson AG, Ezekowitz MD, Ganz P, Oliver MF, Waters D, Zeiher A, Chaitman BR, Leslie S, Stern T, Myocardial Ischemia Reduction with Aggressive Cholesterol Lowering (MIRACL) Study Investigators: Effects of atorvastatin on early recurrent ischemic events in acute coronary syndromes: the MIRACL study: a randomized controlled trial. JAMA 2001;285:1711-1718.

11 Yamauchi T, Kamon J, Minokoshi Y, Ito Y, Waki H, Uchida S, Yamashita S, Noda M, Kita S, Ueki K, Eto K, Akanuma Y, Froguel P, Foufelle F, Ferre P, Carling D, Kimura S, Na- gai R, Kahn BB, Kadowaki T: Adiponectin stimulates glucose utilization and fatty-acid oxidation by activating AMP-activated protein kinase. Nat Med 2002;8:1288-1295.

12 Combs TP, Berg AH, Obici S, Scherer PE, Rossetti L: Endogenous glucose production is inhibited by the adipose-derived protein Acrp30. J Clin Invest 2001;108:1875-1881.

13 Beltowski J: Adiponectin and resistin-new hormones of white adipose tissue. Med Sci Monit 2003;9:RA55-RA61.

14 Ryo M, Nakamura T, Kihara S, Kumada M, Shibazaki S, Takahashi M, Nagai M, Matsuzawa Y, Funahashi T: Adiponectin as a biomarker of the metabolic syndrome. Circ J 2004;68:975-981.

15 Xydakis AM, Case CC, Jones PH, Hoogeveen RC, Liu MY, Smith EO, Nelson KW, Ballantyne CM: Adiponectin, inflammation, and the expression of the metabolic syndrome in obese individuals: the impact of rapid weight loss through caloric restriction. J Clin Endocrinol Metab 2004;89:2697-2703.

16 van Hoek M, van Tol A, van Vark-van der Zee LC, Jansen H, Kastelein JJ, Sijbrands EJ, Dallinga-Thie GM: Role of plasma adiponectin on the HDL-cholesterol raising effect of atorvastatin in patients with type 2 diabetes. Curr Med Res Opin 2009;25:93-101.

17 Zhang Y, Proenca P, Maffei M, Barone M, Leopold L, Friedman JM: Positional cloning of the mouse obese gene and its human homologue. Nature 1994;392:425-432.

18 Chudek J, Wiecek A: Adipose tissue, inflammation and endothelial dysfunction. Pharmacol Rep 2006;58:81-88. 
19 Way JM, Görgün CZ, Tong Q, Uysal KT, Brown KK, Harrington WW, Oliver WR Jr, Willson TM, Kliewer SA, Hotamisligil GS: Adipose tissue resistin expression is severely suppressed in obesity and stimulated by peroxisome proliferator-activated receptor gamma agonists. J Biol Chem 2001;276: 25651-25653.

-20 Curat CA, Wegner V, Sengenès C, Miranville A, Tonus C, Busse R, Bouloumié A: Macrophages in human visceral adipose tissue: increased accumulation in obesity and a source of resistin and visfatin. Diabetologia 2006; 49:744-747.

-21 Shetty GK, Economides PA, Horton ES, Mantzoros CS, Veves A: Circulating adiponectin and resistin levels in relation to metabolic factors, inflammatory markers, and vascular reactivity in diabetic patients and subjects at risk for diabetes. Diabetes Care 2004;27:2450-2457.

-22 Koh KK, Quon MJ, Han SH, Chung WJ, Ahn JY, Seo YH, Choi IS, Shin EK: Additive beneficial effects of fenofibrate combined with atorvastatin in the treatment of combined hyperlipidemia. J Am Coll Cardiol 2005;45: 1649-1653.

>23 Koh KK, Quon MJ, Han SH, Ahn JY, Jin DK, Kim HS, Kim DS, Shin EK: Vascular and metabolic effects of combined therapy with ramipril and simvastatin in patients with type 2 diabetes. Hypertension 2005;45: 1088-1093.

-24 Koh KK, Quon MJ, Han SH, Chung WJ, Ahn JY, Seo YH, Kang MH, Ahn TH, Choi IS, Shin EK: Additive beneficial effects of losartan combined with simvastatin in the treatment of hypercholesterolemic, hypertensive patients. Circulation 2004;110:3687-3692.

>25 Koh KK, Quon MJ, Han SH, Lee Y, Ahn JY, Kim SJ, Koh Y, Shin EK: Simvastatin improves flow-mediated dilation but reduces adiponectin levels and insulin sensitivity in hypercholesterolemic patients. Diabetes Care 2008;31:776-782.
6 Blanco-Colio LM, Martín-Ventura JL, Gómez-Guerrero C, Masramon X, de Teresa E, Farsang C, Gaw A, Gensini G, Leiter LA, Langer A, Egido J: Adiponectin plasma levels are increased by atorvastatin treatment in subjects at high cardiovascular risk. Eur J Pharmacol 2008;586:259-265.

27 Miyagishima K, Hiramitsu S, Kato S, Kato Y, Kitagawa F, Teradaira R, Shinohara R, Mori K, Kimura H, Ueda T, Ohtsuki M, Morimoto S, Hishida H: Efficacy of atorvastatin therapy in ischaemic heart disease - effects on oxidized low-density lipoprotein and adiponectin. J Int Med Res 2007;35:534-539.

28 Ando H, Sugimoto K, Yanagihara H, Tsuruoka S, Saito T, Takamura T, Kaneko S, Fujimura A: Effects of atorvastatin and pravastatin on glucose tolerance, adipokine levels and inflammatory markers in hypercholesterolaemic patients. Clin Exp Pharmacol Physiol 2008;35:1012-1017.

29 Qu HY, Xiao YW, Jiang GH, Wang ZY, Zhang Y, Zhang M: Effect of atorvastatin versus rosuvastatin on levels of serum lipids, inflammatory markers and adiponectin in patients with hypercholesterolemia. Pharm Res 2009;26:958-964.

30 McKenney JM: Pharmacologic options for aggressive low-density lipoprotein cholesterol lowering: benefits versus risk. Am J Cardiol 2005;96:60E-66E.

31 Zhou Z, Rahme E, Pilote L: Are statins created equal? Evidence from randomized trials of pravastatin, simvastatin and atorvastatin for cardiovascular disease prevention. Am Hart J 2006;151:273-281.

32 Ray KK, Cannon CP: Atorvastatin and cardiovascular protection: a review and comparison of recent clinical trials. Expert Opin Pharmacother 2005;6:915-927.
33 National Cholesterol Education Program (NCEP) Expert Panel on Detection, Evaluation, and Treatment of High Blood Cholesterol in Adults (Adult Treatment Panel III): Third Report of the National Cholesterol Education Program (NCEP) Expert Panel on Detection, Evaluation, and Treatment of High Blood Cholesterol in Adults (Adult Treatment Panel III) final report. Circulation 2002;106:3143-3421.

>34 Piecha G, Adamczak M, Chudek J, Wiecek A: Indapamid decreases plasma adiponectin concentration in patients with essential hypertension. Kidney Blood Press Res 2007;30: 187-194.

\35 Katz A, Nambi SS, Mather K, Baron AD, Follmann DA, Sullivan G, Quon MJ: Quantitative insulin sensitivity check index: a simple, accurate method for assessing insulin sensitivity in humans. J Clin Endocrinol Metab 2000;85:2402-2410.

>36 Mäuser W, Perwitz N, Meier B, Fasshauer M, Klein J: Direct adipotropic actions of atorvastatin: differentiation state-dependent induction of apoptosis, modulation of endocrine function, and inhibition of glucose uptake. Eur J Pharmacol 2007;564:37-46.

>37 Ichida Y, Hasegawa G, Fukui M, Obayashi H, Ohta M, Fujinami A, Ohta K, Nakano K, Yoshikawa T, Nakamura N: Effect of atorvastatin on in vitro expression of resistin in adipocytes and monocytes/macrophages and effect of atorvastatin treatment on serum resistin levels in patients with type 2 diabetes. Pharmacology 2006;76:34-39.

-38 Huptas S, Geiss HC, Otto C, Parhofer KG: Effect of atorvastatin (10 mg/day) on glucose metabolism in patients with the metabolic syndrome. Am J Cardiol 2006;98:66-69.

39 von Eynatten M, Schneider JG, Hadziselimovic S, Hamann A, Bierhaus A, Nawroth PP, Dugi KA: Adipocytokines as a novel target for the anti-inflammatory effect of atorvastatin in patients with type 2 diabetes. Diabetes Care 2005;28:754-755. 